\title{
Solid Papillary Breast Carcinoma
}

National Cancer Institute

\section{Source}

National Cancer Institute. Solid Papillary Breast Carcinoma. NCI Thesaurus. Code C6870.

A well circumscribed, low grade neoplasm that arises from the breast. It is characterized by the presence of sheets of malignant epithelial cells that are supported by fibrovascular structures. When there is an invasive component present, it is usually a mucinous carcinoma. 